\title{
Lower limb deformity and prevention of scoliosis in cerebral palsy
}

Sustained motor delay, muscle imbalance, or restricted movement precede the musculoskeletal deformities which complicate many neuromuscular disorders. Infantile alignments, anteversion of the femoral necks, torsion of the tibia and coxa valga are retained, ${ }^{1}$ and infantile postural asymmetry induces a structural asymmetry which lasts several years in normal children, ${ }^{2}$ but persists as scoliosis, pelvic tilting, windswept deformity, and hip dislocation in those with neuromuscular disorders. ${ }^{3}$ Spasticity and muscular hypotonia can coexist: ${ }^{4}$ in the former muscle imbalance produces shortening, or contracture of the stronger muscles, elongation of the weaker muscles, and restricted joint movement. Hypotonia causes lax joints and flat feet.

Contractures seldom occur without hypertonia, and seldom present in the $11 \%$ of 'clumsy' children who have a previously unrecognised mild cerebral palsy ${ }^{5}$ but are common in quadriplegics, with neurological signs and additional handicaps. ${ }^{6}$ For those who teach themselves to stand before the age of 3 the prospects for walking unaided are good, and only about $25 \%$ of the spastic and rigid contractures in this group require surgery, ${ }^{8}$ usually of the calf and hip adductors.

\section{Walking or potentially walking children}

If adequate changes in posture (active or passive) and weight bearing (using a standing frame if necessary) are begun early the skeleton will be appropriately stressed. Improving quality and quantity of voluntary movement is not so easy because mobile children chose efficient, rather than normal looking, ways of moving and reserve their inefficient ways for visits to the clinic; this explains why their anteversion and other torsional abnormalities persist.

A variety of splints and calipers have been devised which attempt to control leg posture and muscle imbalance without affecting mobility. Piedro boots ( $£ 37.00$ to $£ 43.00$ depending on size) stabilise the flat rolled out feet which accompany hypotonia and persistent anteversion. Medial sole and heel wedges (£3.00 each), possibly floated outwards $(£ 5.00)$, may be added. A below knee outside iron (£34.00), round heel socket $(£ 13.00)$, and inside $T$ strap $(£ 9 \cdot 00)$ will support a lax ankle or counteract peroneal overactivity. Overaction or early contracture of calf muscles may be controlled by a $90^{\circ}$ backstop to prevent plantarflexion of the boot. If the foot is not dorsiflexed the child's heel remains high and produces a horizontal crease around the upper boot heel; an internal strap to restrain the heel is needed to hold the foot in place. The plastic Ankle-Foot Orthosis $(£ 80.00)$ is moulded to fit the contours of the calf, heel, and sole, and is worn under ordinary stockings and shoes to reduce plantarflexion and control foot posture. (The prices quoted were current in December 1986.)

Serial below knee plastering to reduce established calf contracture was abandoned in the 1960s, as the force applied produced flat 'rocker bottom' feet. Its use in treating equinus gait without contracture has continued, ${ }^{9}$ and has been extended to treat early contractures and equinus postures. Controlled trials ${ }^{1011}$ have shown reduction in equinus lasting six months, with improved gait for up to one year.

Non-sedative muscle relaxants such as baclofen improve voluntary movement hindered by hypertonia, ${ }^{12}$ and the new liquid formulation $(5 \mathrm{mg} / 5 \mathrm{ml})$ permits fine adjustment of the dose in infants. Relaxants may be used in conjunction with appliances to control hypertonia, but the combination of hypertonia, trunk and limb hypotonia, and weakness in many children means that results are unpredictable.

Mild hip adduction/internal rotation/flexion postures of the hips and flexion contractures of the knees are not easily influenced by small light appliances and are best tolerated provided they are neither worsening nor seriously interfering with free walking. Passive hip abduction of less than $30^{\circ}$ is one factor which starts spontaneous dislocation and must be dealt with surgically.

\section{Non-walking children}

In severely handicapped children neither passive movement nor induced active movement can ever replicate the normal child's repertoire of daily movements, but they need frequent changes in posture to offset the continuous decerebrate or decorticate postures. Where little voluntary movement exists, appliances which maintain a posture at the expense of mobility are acceptable, and often 
take the form of special adaptations to the child's chair. Usually, the child's contractures are best dealt with surgically as poor trunk control is exacerbated by muscle relaxants, and without specific muscle relaxation or elongation there is little chance of maintaining alternative postures and thereby preventing future deformity.

Scoliosis, pelvic obliquity, and 'windswept hips' affect both hypotonic and hypertonic profoundly retarded children. Adducted hips dislocate first. The initiating postural asymmetry ${ }^{13}$ can be controlled by a plagiocephaly helmet ${ }^{14}$ and by plastic foam moulds, combined with early prone lying and symmetrical active movement treatment, ${ }^{15}$ which should be begun in the first year before structural changes occur. Once these are present, the hip and pelvic position needs to be controlled by special chair adaptations, prone lying apparatus, standing frame, and wedged cushions between the knees, using a large towel as a sling to keep the adducted hip in abduction when lying supine both day and night. Adductor tenotomy or obturator neuronectomy may be necessary to attain adequate abductions as this reduces the chance of posterior hip dislocation and improves sitting posture.

Apparatus which controls head, pelvis, and lower limb asymmetry also affects trunk postural mechanisms and thus deals with simple correctable (postural) scoliotic curves. Deteriorating, complex, and fixed curves, however, require the special clinical and orthotic expertise afforded by a scoliosis clinic.

\section{References}

' Bunch W. Origin and mechanism of postnatal deformities. Pediatr Clin North Am 1977;24:679-84.

${ }^{2}$ Robson P. Persisting head turning in the early months: some effects in the early years. Dev Med Child Neurol 1968;10:82-92.
${ }^{3}$ Fulford GE, Brown JK. Position as a cause of deformity in children with cerebral palsy. Dev Med Child Neurol 1976;18:305-14.

4 Robson P, MacKeith RC. Shufflers with spastic diplegic cerebral palsy: a confusing clinical picture. Dev Med Child Neurol 1971;13:651-9.

5 Dare MT, Gordon N. Clumsy children: a disorder of perception and motor organisation. Dev Med Child Neurol 1970;12:178-85.

${ }^{\circ}$ Robinson RO. The frequency of other handicaps in children with cerebral palsy. Dev Med Child Neurol 1973;15:305-10.

${ }^{7}$ Beales RK. Spastic paraplegia and diplegia. An evaluation of non-surgical and surgical factors influencing the prognosis for ambulation. J Bone Joint Surg 1966;48A:827-46.

$\times$ Banks HH. The foot and ankle in cerebral palsy in orthopaedic aspects of cerebral palsy. In: Samilson RL, ed. Clinics in developmental medicine No 52/53. London: William Heinemann, 1975:19.

${ }^{9}$ Fixsen JA. Surgical treatment of the lower limbs in cerebral palsy: a review. J Roy Soc Med 1979:72:761-5.

11 Watt J, Sims D, Harckham F, Schmidt L, McMillan A, Hamilton J. A prospective study of inhibitive casting as an adjunct to physiotherapy for cerebral palsied children. Dev Med Child Neurol 1986;28:480-8.

$"$ Bertoli DB. Effects of short leg casting on ambulation in children with cerebral palsy. Phys Ther 1986:66:1522-9.

12 Milla JP, Jackson ADM. A controlled trial of baclofen in children with cerebral palsy. J Int Med Res 1977;5:398-404.

13 Brown JK. Positional deformity in children with cerebral palsy. Physiotherapy Practice 1985;1:37-41.

14 Clarren SK, Smith DW, Hanson JW. Helmet treatment for plagiocephaly and congenital muscular torticollis. J Pediatr 1979;94:43-6.

15 Scrutton DR. Aim orientated management. Management of the motor disorders of children with cerebral palsy. In: Scrutton DR, ed. Clinics in developmental medicine no 90. Oxford: Blackwell Scientific Publications, 1984:149.

P RoBson

Department of Child Health, King's College Hospital, Denmark Hill, London SE5 9RX. 